\title{
FACTORS INFLUENCING THE PREPARATION, SUPPORT AND TRAINING OF SOUTH AFRICAN EXPATRIATES
}

\author{
AJ Vögel \& JJ van Vuuren, Dept of Business Management, University of Pretoria, South Africa.
}

\begin{abstract}
Purpose: The purpose of this paper is to determine if the independent variables; location of an international assignment, the age of an expatriate, the duration of an assignment and the management level of an expatriate, influence the preparation, support and training that they require for an international assignment.
\end{abstract}

Design/Methodology/Approach: This formal, empirical study was undertaken using an electronic questionnaire that was distributed to expatriates who were on an international assignment. Expatriates who were on an international assignment were thought to be in the best position to respond to their preparation, support and training needs.

Findings: The research found that the preparation, support and training required by South African expatriates are not influenced by the location of an international assignment, the age of the expatriate, the duration of an international assignment or the management level of the expatriate.

Implications: The findings highlight the fact that human resource managers of South African multinational enterprises should provide all their expatriates with the same preparation, support and training, as well as identifies five requirements that should be included in all South African expatriate policies.

Key words and phrases: Expatriate, international human resource management, expatriate preparation, support and training.

\section{INTRODUCTION}

Though many larger enterprises are attempting to stabilise or reduce their number of international assignments, internationally the expatriate workforce is growing caused by a steady increase in smalland medium-sized enterprises entering the international marketplace (Fitzgerald-Turner, 1997:70; Feldman \& Thomas, 1992:271 and Scullion, 1994:89). MNEs use expatriates for various reasons, including: their knowledge of the MNEs' processes, products and services (Özbilgin, 2005:97 and Scullion \& Linehan, 2005:120); a lack of competent host country managers (Feldman \& Thomas, 1992:271; Hill, 2006:620-623 and Scullion, 1994:90), and international assignment are being used for management development (Scullion, 1994:90; Ball et al., 2006:546 and Feldman \& Thomas, 1992:271).

A major problem facing these MNEs, however, has been the failure - the premature return - of expatriates (Shaffer \& Harrison, 1998:87; Black, 1988:277; Black, Mendenhall \& Oddou, 1991:291 and Tung, 1982:67-69). The failure rate of expatriates seems to vary depending on the study, but can range anywhere between 10 and 80 percent (Tung, 1982:67-69; Shaffer \& Harrison, 1998:87; Shay \& Tracey, 1997:31 and Briscoe \& Schuler, 2004:243-244). It should, however, be kept in mind that failure varies in degree and that expatriates who remain on the assignment but psychologically withdraw may incur indirect losses for their enterprise (Shaffer \& Harrison, 1998:87 and Copeland \& Griggs in Shay \& Tracey, 1997:31). According to Shaffer and Harrison (1998:87), these losses can include a reduction in productivity, market share, and competitive position, as well as damaged staff, customer and supplier relations, and discredited corporate image and reputation. For the purpose of this study, however, failure will only refer to the early termination of an assignment.

The high costs of failed expatriate assignments has also been well documented and according to numerous studies can range anywhere between US $\$ 40000$ and US\$1 million (McNerney, 1996:1; Shay \& Tracey, 1997:31; Hill, 2006:624 and Griffin \& Pustay, 2002:583).

Facing this problem, the literature suggests that the success of an international assignment can be ensured if effective preparation, support, and training were provided to the expatriate, their trailing spouse and trailing family (Fontaine, 1997:631; Bross in Anon, 2000a:61 and Black et al., 1991:293). However, most of the research seems to suggest that MNEs are not providing the preparation, support and training required by expatriates. According to the second annual Global Expatriate 
Study, nearly 40 percent of the 709 expatriate respondents stated they were not prepared adequately for an international assignment, 56 percent cited poor coordination between local-country and homeoffice HR departments, and 35 percent said they expected to leave their current employer within five years. Adding to this, the survey also found that employees working in other countries want their enterprises to provide them with security bulletins, contingency plans and emergency guidelines to keep them up to date about potential adverse conditions, but only 20 percent of the respondents indicated that their enterprises were keeping them informed (Britt, 2002:21-22).

In the 1996-1997 International Assignee Research Project, 65 percent of international transferees surveyed were not provided with a pre-departure medical briefing about benefits and in-country practices, and 38 percent were not offered pre-departure medical exams or immunisations (Frazee, 1998:23). In a study of 74 executives of multinational enterprises in the United States (US), it was found that only 23 believed knowledge of foreign languages was necessary for conducting business abroad (Hill, 2006:628)

Apart form the fact that expatriates do not seem to receive the preparation, support and training they require, the literature further suggests that the preparation, support and training provided to an expatriate, their trailing spouse, and their trailing family is influenced by the management level of the expatriate (Harvey, 1995:233) as well as the degree of integration and the duration of the international assignment (Beamish, Morrison, Rosenzweig \& Inkpen, 2000:193). It is further suggested that the expatriate's age (Hodgetts \& Luthans, 2003: 451), and the location of an international assignment (Tung, 1982:68; Shay \& Tracey, 1997:31) can influence the success of such an assignment.

As there is a lack of research on the preparation, support and training of South African expatriates, this research aimed to determine the factors influencing the preparation, support and training required by South African expatriates. In answering this question, this paper will first focus on the research objectives and literature review in order to determine the stated hypotheses and motivation for the hypotheses. Next, the findings of the empirical research will be discussed followed by the implications of and recommendations from the research.

\section{RESEARCH OBJECTIVES AND LITERATURE REVIEW}

In an attempt to answer the above stated question, a number of hypotheses were stated and tested.

According to Shay and Tracey (1997:31), 25 to 40 percent of US expatriates assigned to a developed country return home prematurely compared to 70 percent assigned to a developing country. The higher failure rate of expatriates assigned to certain locations is further highlighted when considering that MNEs are paying their expatriates assigned to international destinations considered to be an extremely disagreeable location (hardship posts) overseas premiums - a percentage of their base salary - as compensation for the location (Ball et al., 2006:556 and Griffin \& Pustay, 2003:590). Briscoe and Schuler (2004:317) provides an example of what US MNEs are paying as overseas premiums (percentage of base pay) to expatriates assigned to the Middle East; United Arab Emirates (12.5 percent), Bahrain (20 percent), Egypt (20 percent), Saudi Arabia (25 percent), and Israel (42.5 percent). MNEs also make contract termination payments to expatriates on international assignments in a hardship or disagreeable location as an incentive to stay the full duration of the assignment (Ball et al., 2006:557). As the location of an international assignment seems to influences the failure rate and compensation of expatriates it was hypothesised that:

$\mathrm{H}_{10}$ : There is no difference between the preparation, support and training needs of expatriates on an international assignment in Africa and those of expatriates on an international assignment in the rest of the world.

$\mathrm{H}_{1 \mathrm{~A}}$ : There is a difference between the preparation, support and training needs of expatriates on an international assignment in Africa and those of expatriates on an international assignment in the rest of the world.

Secondly, the literature shows that the duration of an assignment can influence the type and amount of training that an expatriate should receive. According to Beamish et al. (2000:193), the amount of training provided to an expatriate should be influenced by the amount of cultural exposure to which he or she will be subjected. According to the authors, two dimensions of cultural exposure are the 
degree of integration and the duration of an assignment. A person could be sent to a foreign nation on a short-term, technical, troubleshooting matter and experience little significant contact with the local culture. On the other hand, a person could be in a foreign country for only a brief visit to negotiate a contract, but the cultural interaction could be very intense and might require a greater deal of cultural fluency to be successful. Similarly, an expatriate assigned to a foreign country for a number of years will experience a high degree of interaction with the local culture from living there.

Beamish et al. (2000:193-194) recommends that for short assignments (less than a month) and a low level of integration, an "information-giving approach" would suffice. This might include area and cultural briefings and survival-level language training. For a longer assignment of for example 2-12 months, with a moderate level of integration, an MNE should consider providing language training, role-playing, case studies, and stress reduction training. When expatriates will be living abroad for one to three years and will be experiencing a high level of integration into the culture, MNEs should consider providing extensive language training, sensitivity training, field experience, and simulations. This is supported by Wild, Wild and Han (2003:461-462) when stating that the methods used to prepare managers for an international assignment tend to reflect a manager's level of international involvement. As a result, it was hypothesised that:

$\mathrm{H}_{20}$ : There is no relationship between the duration of international assignments and the type of preparation, support and training that expatriates feel they need for international assignments.

$\mathrm{H}_{2 \mathrm{~A}}$ : There is a relationship between the duration of international assignments and the type of preparation, support and training that expatriates feel they need for international assignments.

Thirdly, a very recent trend in British and Irish MNEs - 26 out of 45 enterprises surveyed - seems to be the tendency to give younger managers international experience much earlier in their careers than previously. This can be linked to the growing problems of mobility (spouse's job, children's' education, etc.) for older managers. This also reflects the strategy of some MNEs to broaden the opportunities for international development, and the assumption that the payback on the investment of a developmental assignment may be greater with a younger manager (Scullion, 1994:91-92). According to Blue and Haynes (1977:64-65), and Hodgetts and Luthans (2003:453), younger managers are much more enthusiastic about an international assignment and tend to be more adaptable to the new environment such as the culture of the foreign nation. However, they tend to lack experience in organising work, managing people and lack product knowledge. This necessitates the need for MNEs to send a team made up of both young manages with enthusiasm and adaptability and older more experienced managers. Hodgetts and Luthans (2003:451) further adds that expatriates over 35 years of age tend to have slightly higher levels of satisfaction after the first year; but expatriates under 35 have higher satisfaction during the next three to four years. As age, according to the literature, influences the selection and satisfaction of expatriates, it was hypothesised that:

$\mathrm{H}_{30}$ : There is no relationship between the age group that expatriates fall into and the type of preparation, support and training that they feel they need for international assignments.

$\mathrm{H}_{3 \mathrm{~A}}$ : There is a relationship between the age group that expatriates fall into and the type of preparation, support and training that they feel they need for international assignments.

Lastly, the research aimed to determine if the management level of an expatriate influenced the preparation, support and training expatriates require. In one study, Harvey (1995:233) attempted to determine the type and quality of assistance offered to the trailing spouse and families of expatriates before, during and after an international assignment. In the study, it was determined that the trailing spouse and family of executive level expatriates received the following assistance prior to the assignment:

- Training programmes

- Educational support

- Introductions/recommendations to other enterprises in host countries

- Assistance with government requirements and/or restrictions, e.g., employment visas 
The assistance offered to the trailing spouse and family of lower level expatriates were, however, found to be lower for middle and supervisory level expatriate managers. Supervisory level managers received even less assistance than middle managers (Harvey, 1995:233).

During the assignment, both executive and middle managers received a great deal of support, with the most frequently mentioned support systems being (Harvey, 1995:233):

- Educational opportunities

- Extended adjustment time during relocation

- Introduction/recommendations to other enterprises in the host country

- Assistance in job search and obtaining work permits

Apart from assistance with government requirements, a supervisory level manager's trailing spouse and family appear to receive 50 percent less assistance during an assignment than the spouses and families of executive and middle management expatriates (Harvey, 1995:233). As a result of the findings by Harvey (1995), it was hypothesised that:

$\mathrm{H}_{40}$ : There is no difference in the preparation, support and training needs of top and middle management expatriates on an international assignment.

$\mathrm{H}_{4 \mathrm{~A}}$ : There is a difference in the preparation, support and training needs of top and middle management expatriates on an international assignment.

When looking at the literature and the stated hypotheses, it would seem that the preparation, support and training offered to expatriates are influenced by two groups of variables, namely assignment related variables - location and duration - and expatriate related variables - age and the expatriate's level within the management hierarchy.

\section{RESEARCH METHODOLOGY}

The following methodology was used in testing the hypotheses.

\section{The Measuring Instrument}

The research was started with a study of the international human resource and expatriate management literature in an attempt to gain insight into the preparation, support and training of expatriates and their trailing families. The literature study was further supplemented with a literature study of the expatriation policies of two international - non-South African - MNEs in order to ensure that a comprehensive - though not exhaustive - list of preparation, support and training criteria could be determine with which an electronic questionnaire could be compiled.

The web-based questionnaire consisted of six demographic questions and 60 statements linked to a four point Likert-type scale. The 60 statements further consisted of 24 statements measuring preparation, 16 statements measuring support, seven statements measuring training, eight statements measuring spouses' needs and five statements measuring the needs of the expatriates' children.

\section{The Sample}

Non-probability judgment sampling was used, as only South African MNEs who make use of expatriates could be used in this study. The human resource managers of 48 South African MNEs were approached in an attempt to determine if they made use of expatriates. Those responding positively were then asked to participate in the research which required them to provide the researcher with a list of their expatriate managers as well as their e-mail addresses in order for the questionnaire to be distributed to them. Only expatriates who were at that stage on an international assignment were included in the research as they were considered to be in the best position to respond to their preparation, support and training needs.

Of these 48 MNEs, eight were willing to participate in the research and 102 questionnaires were sent out. Of these, only 80 were sent to addresses that were still active. A further six MNEs offered to send 
the questionnaire to their expatriates personally, meaning that an undisclosed number of questionnaires were sent out by these MNEs.

Additionally a London-based enterprise specialising in expatriate and other international human resource management issues sent the questionnaire to their South African members asking them to participate in the research. As their membership records are confidential, it is not known how many questionnaires were completed by their members. Lastly, five MNEs indicated that they did not make use of expatriates. The end result of this process was a total of 65 respondents. According to Black (1988:283), this is a typical response rate for expatriate research. In a study of US expatriates in Japan, Black (1988) sent out 195 questionnaires of which 77 were returned for a response rate of 40 percent. Of the 77 returned questionnaires only 67 were usable.

\section{Statistical Analysis of the Data}

The data analysis was done in two phases. First the internal-consistency reliability of the measurement tool was tested using Cronbach's coefficient alpha. Secondly, due to the small sample size, chi-square could not be used to test the hypotheses and as a result Fisher's exact test was used. Using the Fisher's exact test meant that the independent variable for each hypothesis needed to consist of two groups (e.g. age needed to be divided into 35 and under; and older than 35). At the same time, the four point Likert scale needed to be combined into two groups; agree and disagree dependent variable.

\section{RESULTS}

The following results were obtained through the data analysis.

\section{Reliability Results}

According to Cooper and Schindler (2003:216-217), when testing for reliability, a Cronbach's alpha value of above 0.5 is regarded as an indication of reliability and, as can be seen from table 1 , the values for all five factors are above 0.7 , indicating the reliability of the measurements.

\section{Table 1: Cronbach's alpha values}

\begin{tabular}{|l|l|}
\hline Variables & Required \\
\hline Cronbach's alpha results for Preparation (24 Variables) & 0.819536 \\
\hline Cronbach's alpha results for Support (16 Variables) & 0.773405 \\
\hline Cronbach's alpha results for Training (7 Variables) & 0.849970 \\
\hline Cronbach's alpha results for Spouses (8 Variables) & 0.802050 \\
\hline Cronbach's alpha results for Children (5Variables) & 0.782243 \\
\hline
\end{tabular}

\section{Demographic Profile of the Sample}

The majority of respondents in this study, namely 40, were assigned to African countries with 13 being assigned to Europe, eight to Asia and two to Australasia. In terms of their age, the respondents' ages varied between 23 and 60 years. The largest percentage of respondents was married with 78 percent, while 88.89 percent of the respondents were male. These findings correlate highly with those in the USA where 78 percent of expatriates are married and 90 percent are male (Harvey, 1995:223).

The length of expatriate assignments in this study varied from seven to 120 months with the greatest percentage, namely 38 , lasting for 36 months. The majority of respondents held top management positions - 30 respondents - 27 held middle management positions, five were in a supervisory position and three in non-managerial positions.

\section{Fisher Exact Test Results}

The first group of independent variables studied for their potential influence on the preparation, support and training needs of South African expatriates were focused on the assignment itself and specifically on the location and the duration of the assignment. 
In testing if the location of an assignment influenced the preparation, support and training requirements of expatriates, expatriate assignments in Africa were compared to those in the rest of the world. The findings, however, showed that at a significance level of $p \leq 0.05$, the only statistically significant difference between expatriates being sent to Africa and expatriates being sent to the rest of the world was:

- The MNE should provide expatriates with a list of property rental agents in the host country to assist them in finding a rental property $(p<0.0444)$. While 75 percent of expatriates on an assignment in Africa agreed with this statement, 95.65 percent of expatriates on assignment to the rest of the world agreed.

When the significance level was, however, decreased to $p \leq 0.10$, a further three variables showed statistically significant differences between Africa and the rest of the world, namely:

- The MNE should ship the personal automobile of an expatriate to or from the host country $(p<0.0697)$. While 60 percent of expatriates on an assignment in Africa agreed with this statement, only 34.78 percent of expatriates on assignment in the rest of the world agreed.

- The MNE should provide the expatriate with legal assistance in drawing up or updating a will prior to their departure $(p<0.0542)$. Only 57.50 percent of expatriates on assignment in Africa agreed with this statement, while 82.61 percent of expatriates in the rest of the world agreed.

- The MNE should assist the spouse of an expatriate in acquiring a work permit for the host country $(p<0.0754)$. While 81 percent of the expatriates in Africa agreed with the statement, 100 percent of the expatriates in the rest of the world agreed.

As only one of the 60 variables showed statistically significant differences at a significance level of $\mathrm{p} \leq 0.05$, the null hypothesis $\left(\mathrm{H}_{10}\right.$ : There is no difference between the preparation, support and training needs of expatriates on an international assignment in Africa and those expatriates on an international assignment in the rest of the world) can be accepted.

In testing the second independent variable - assignment duration - the response categories were combined into 0-4 years and longer than 4 years. Here the results showed that, at a significance level of $p \leq 0.05$, only two variables showed a statistically significant difference between the duration of an international assignment and the preparation, support and training required by an expatriate:

- Prior to the assignment, the expatriate and his or her spouse should be allowed to visit the host country for an orientation visit at the MNEs' expense $(p<0.0356)$. While 98 percent of expatriates on an assignment of four years or less agreed with this statement, 80 percent of the expatriates on an assignment of over four years agreed.

- Spouses should receive cross-cultural training focusing on subjective characteristics of the host culture such as: customs, values and beliefs $(p<0.0352)$. Of those expatriates on an assignment of four years or less, 81.58 percent agreed with this statement, while only 50 percent of the expatriates on an assignment of more than four years agreed.

When the significance level was reduced to $p \leq 0.10$, one more variable was added to the list of variables with a statistically significant difference, namely:

- The MNE should provide assistance to the expatriate in negotiating the terms of a property lease agreement in the host country $(p<0.0749)$. While 83.67 percent of the expatriates on an assignment of four years or less agreed with this statement, only 60 percent of the expatriates on an assignment of longer than four years agreed.

As there are statistically significant differences in only two of the 60 variables at a significance level of $p \leq 0.05$, the null hypotheses $\left(\mathrm{H}_{30}\right.$ : There is no relationship between the duration of international assignments and the type of preparation, support and training that expatriates feel they need for these assignments) is accepted. 
The results thus indicate that neither of the assignment related variables - location or duration influence the preparation, support and training required by South African expatriates.

The second group of independent variables studied focused on factors related to the expatriate, namely; the age of the expatriate and the managerial position held by the expatriate.

The ages of expatriates in this study ranged from 23 to 60 , but for the purpose of this study were combined into 35 and under; and older than 35 . At a significance level of $p \leq 0.05$, three variables showed a statistically significant relationship between the age of an expatriate and the preparation, support and training they require, namely:

- The MNE should pay for the storage and insurance of those household goods and other belongings remaining in the home country $(p<0.0302)$. While 85.71 percent of the expatriates 35 years and under agreed with the statement, 100 percent of the expatriates older than 35 agreed.

- The MNE should provide the expatriate with legal assistance in drawing up or updating a will prior to their departure $(p<0.0357)$. While 82.14 percent of expatriates 35 and under agreed with the statement, only 56.76 percent of expatriates over 35 agreed.

- The MNE should provide assistance to an expatriate's spouse in finding work in the host country $(p<0.0011)$. While 90 percent of expatriates 35 and under agreed with this statement, only 43.75 percent of expatriates over 35 agreed.

If the significance level is, however, reduced to $p \leq 0.10$, two more variables show a statistically significant difference:

- The MNE should provide the expatriate with reading material such as newspapers from the host country in order to prepare for the new location ( $p<0.0614)$. While 82.14 percent of expatriates 35 years and under agreed with this statement, only 59.46 percent of the expatriates over 35 agreed.

- Expatriates should receive cross-cultural training focusing on subjective characteristics of the host culture such as: customs, values and beliefs $(p<0.0662)$. While 96.43 percent of expatriates 35 and under wished to receive subjective cross-cultural training, only 78.38 percent of expatriates over 35 wished to receive the same training.

As with the previous two hypotheses, a very small number of variables - three out of 60 - showed a statistically significant differences at a significance level of $p \leq 0.05$ and, as a result, the null hypothesis $\left(\mathrm{H}_{20}\right.$ : There is no relationship between the age group that expatriates fall into and the type of preparation, support and training they feel they need for international assignments) was accepted.

The second expatriate related variable focused on the management position held by the expatriate. As the hypothesis only focuses on two management levels - top and middle management - there was no need to combine any response categories. At a significance level of $p \leq 0.05$, only one variable showed a statistically significant difference between the preparation, support and training required by top and middle managers, namely:

- The MNE should assist an expatriate's spouse in acquiring a work permit for the host country $(p<0.0099)$. One hundred percent of middle managers agreed with this statement, while only 72 percent of top managers agreed.

If the significance level is reduced to $p \leq 0.10$, a further three variables can be added, namely:

- The MNE should administer or assist with the administration of the rental of the primary residence of an expatriate while on an international assignment $(p<0.0644)$. While 70.37 percent of middle managers agreed with this statement, only 44.83 percent of top managers agreed. 
- MNEs should involve the spouse of an expatriate in the original information and orientation sessions prior to accepting the assignment $(p<0.0507)$. All the middle managers agreed with this statement, while 80 percent of the top managers agreed.

- The MNE should provide assistance to an expatriate's spouse in finding work in the host country $(p<0.0832)$. While 73.91 percent of middle managers agreed with this statement, only 48 percent of top managers agreed.

As the results of the Fisher exact test for the last hypothesis indicate that at a significance level of $p \leq 0.05$, only one of the 60 variables show any statistically significant difference between the preparation, support and training needs of top and middle managers. The null hypotheses $\left(\mathrm{H}_{40}\right.$ : There is no difference between the preparation, support and training needs of top and middle management expatriates on an international assignment) can also be accepted.

\section{IMPLICATIONS AND RECOMMENDATIONS}

The findings of this research suggest that, although the preparation, support and training of expatriates are important, South African MNEs do not need to provide specially modified preparation, support and training programmes and policies to their expatriates. As was seen in the previous section, the location of an assignment, the duration of the assignment, the age of the expatriate and the management level of the expatriate, do not influence their preparation, support and training needs.

A notable finding of the research, however, was that all respondents were always 100 percent in agreement with five requirements, irrespective of the independent variable being tested, namely:

- The MNE should pay for the shipping and insurance costs of the expatriate's household belongings to the host country.

- The MNE should cover the temporary living expenses of expatriates and their families living in a hotel or furnished apartment prior to moving into their new residence in the host country.

- The MNE should once a year provide the expatriate and his/her family with plane tickets to the home country in order to take home leave.

- The MNE should provide round-trip plane tickets to the expatriate and his/her family in the case of illness or death in their immediate family.

- An education allowance (tuition only) should be provided to the expatriate in order to ensure that their children will receive schooling equal to that, which they would have received in South Africa.

As it was determined that South African expatriates currently on an international assignment feel very strongly about these five requirements, it is recommended that they should form the minimum requirements of the expatriate preparation, support and training programme and policy of a South African MNE.

\section{CONCLUSION}

A review of the international human resource management literature indicated that the failure premature termination of an international assignment - of expatriates is a major problem for MNEs with the failure rates ranging between 10 and 80 percent. These failed assignments also have a major financial implication for an MNE with a failed assignment coasting an MNE anywhere between US\$ 40000 and US\$ 1 million. In an attempt to reduce this high failure rate, research suggests that MNEs should provide expatriates, their trailing spouse and trailing families with preparation, support and training to enable them to better adjust to the new environment.

The literature, however, suggests that the preparation, support and training offered should be or is often adjusted according to the location of an international assignment, the duration of the assignment, the age of the expatriate, and the management level of the expatriate. As most of these 
studies were focused on or originated in either the USA or Western Europe, very little was known about the South African situation and whether this research can be applied to South African MNEs.

The focus on South African MNEs seems to be justified as the research found that irrespective of the assignment related variables - location and duration of the assignment - or the expatriate related variables - age and management level of the expatriate, all expatriates require the same preparation, support and training. It should, however, be kept in mind that, due to the small sample size, the independent variables were grouped into rather large groupings and a more refined study might identify more specific differences in smaller groupings, for example more specific differences between age groups.

\section{REFERENCES}

Anon. 2000a. Getting smart about going global. Workforce, 79(7):58-61.

Ball DA, McCulloch Jr WH, Frantz PL, Geringer JM \& Minor MS. 2006. International Business: The challenges of global competition. 10th ed. New York: McGraw-Hill Irwin.

Beamish PW, Morrison AJ, Rosenzweig PM \& Inkpen AC. 2000. International management: Text and cases. 4th ed. Boston: Irwin McGraw-Hill.

Black JS. 1988. Work role transitions: A study of American expatriate managers in Japan. Journal of International Business Studies, 19(2):277-294.

Black JS, Mendenhall M \& Oddou G. 1991. Towards a comprehensive model of international adjustment: An integration of multiple theoretical perspectives. Academy of Management Review, 16(2):291-317.

Blue JL \& Haynes U. 1977. Preparation for the overseas assignment. Business Horizons, June: 6167.

Briscoe DR \& Schuler RS. 2004. International human resource management. 2nd ed. London: Routledge Taylor \& Francis Group.

Britt J. 2002. Expatriates want more support from home. HR Magazine, 47(7):21-22.

Cooper DR \& Schindler PS. 2003. Business Research Methods. 8th ed. New York: McGraw-Hill Irwin.

Feldman DC \& Thomas DC. 1992. Career management issues facing expatriates. Journal of International Business Studies, 23(2):271-293.

Fitzgerald-Turner B. 1997. Myths of expatriate life. HR Magazine, 42(6):65-74.

Fontaine G. 1997. Skills for successful international assignments to, from and within Asia and the Pacific: Implications for preparation, support and training. Management Decisions, 35(8):631-642.

Frazee V. 1998. Keeping your expats healthy. Workforce, November: 19-23.

Griffin RW \& Pustay MW. 2002. International business: A managerial perspective. 3rd ed. Upper Saddle River: Prentice Hall.

Harvey MG. 1995. The impact of dual-career families on international relocations. Human Resource Management Review, 5(3): 223-244.

Hill CWL. 2006. International business: Competing in the global marketplace. 6th ed. New York: McGraw-Hill Irwin. 
Hodgetts RM \& Luthans F. 2003. International management: Culture, strategy and behaviour. $5^{\text {th }}$ ed. New York: McGraw-Hill Irwin.

McNerney DJ. 1996. Global staffing: Some common problems - and solutions. HR Focus, 73(6):1-6.

Özbilgin M. 2005. International human resource management, theory and practice. New York: Palgrave Macmillan.

Scullion H. 1994. Staffing policies and strategic control in British multinationals. International Studies of Management and Organisation, 24(3):86-103.

Scullion H \& Linehan M. 2005. International human resource management: A critical text. New York: Palgrave Macmillan.

Shaffer MA \& Harrison DA. 1998. Expatriates' psychological withdrawal from international assignments: Work, nonwork and family influences. Personnel Psychology, 51(1):87-118.

Shay J \& Tracey JB. 1997. Expatriate managers: Reasons for failure and implications for training. Cornell Hotel and Restaurant Administration Quarterly, February:30-35.

Tung RL. 1982. Selection and training procedures of U.S., European, and Japanese multinationals. California Management Review, 25(1):57-71.

Wild JJ, Wild KL \& Han JCY. 2003. International business. 2nd ed. Upper Saddle River: Prentice Hall. 